\title{
Testicular and Paratesticular Tumors in Children
}

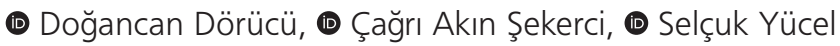 \\ Marmara University Faculty of Medicine, Department of Urology, Istanbul, Turkey
}

\begin{abstract}
Testicular and paratesticular tumors are rare in the prepubertal age group as compared with the postpubertal period and adulthood. Testicular tumors are separated mainly into two groups; germ cell tumors (teratoma, yolk sac tumors, epidermoid cyst) and gonadal stromal tumors (Juvenile granulosa cell, Leydig cell, and Sertoli cell tumors). Paratesticular tumors can either be lipomas, leiomyomas, hemangiomas, or rhabdomyosarcomas. Physical examination, serum markers, and the scrotal ultrasound have an important role in their diagnosis. Testes-sparing surgery is gaining more grounds in children owing to the dominancy of benign tumors. In malignant tumors, radical orchiectomy and selective chemotherapy are standard approaches. Radiotherapy and retroperitoneal lymph node dissection have a minimal role in treatment.
\end{abstract}

Keywords: Testis tumors, children, radical inguinal orchiectomy, testis-sparing surgery, yolk sac tumor, paratesticular rhabdomyosarcoma

\section{Introduction}

Testicular tumors (TT) are rarely seen in the prepubertal period, and benign lesions are more common in childhood. These tumors are approximately $1 \%$ of all pediatric solid tumors and their incidence ranges from 0.5 to 2 per 100,000 (1). Germ cell tumors (GCT) constitute $95 \%$ of TT in adulthood, but this rate is only $60-75 \%$ in children (2). However, the fact that the TT in children is more benign compared to adults affects management strategies (3). Although radical inguinal orchiectomy (RIO) is the gold standard, testis-sparing surgery (TSS) may also be a standard of choice in children $(4,5)$.

Paratesticular tumors originate from tunica vaginalis, epididymis, or spermatic cord, and appear as rhabdomyosarcoma [(RMS) representing 40\%]. Approximately $15-20 \%$ of RMS is of genitourinary origin and it is more benign compared to the other forms (6).

Diagnosing and treating testicular and paratesticular tumors remarkably different with different age groups. Thus, the aim of this article is to review the characteristics and treatment modalities of testicular and paratesticular tumors in children under the light of the current literature.

\section{Epidemiology}

Relevant data about $\mathrm{TT}$ in children was obtained from the prepubertal testis tumor registry (PTTR). TT peaks twice; before the age of 3 and after puberty (1). According to PTTR data, yolk sac tumor (YST) is the most common type with $62 \%$ prevalence, followed by teratomas with $23 \%$ (Table 1) $(3,7)$. Similarly, a recent study from the National Cancer Database reported that YSTs are the most common pathology; however, this registry does not record benign lesions such as teratoma (8). Some studies have reported findings that differ from the PTTR. In a multicenter study involving 98 patients, the most common types were teratoma (48\%), YST (15\%), and epidermoid cyst (14\%). In the same study, gonadal stromal tumors were detected in $13 \%$ of all patients (9). In another study involving 51 patients, the incidence of mature teratoma, RMS, epidermoid cyst, YST, and others were reported as $47 \%, 27 \%, 10 \%, 8 \%$, and $8 \%$, respectively (4). The most common paratesticular tumors were RMS. Paratesticular RMS accounts for $75 \%$ of all RMS $(6,10)$ and

\begin{tabular}{|l|l|}
\hline $\begin{array}{l}|l| \\
\text { Table 1. Incidence of pediatric TT according to prepubertal testis } \\
\text { tumor registry (3) }\end{array}$ & Percent (\%) \\
\hline Tumor type & 62 \\
\hline Germ cell tumors & 23 \\
\hline Yolk sac tumor & 3 \\
Teratoma & \multicolumn{2}{|l|}{} \\
Epidermoid cyst & 3 \\
\hline Gonadal stromal tumors & 3 \\
\hline Juvenile granulosa cell & 1 \\
Sertoli cell & 4 \\
Leydig cell & 1 \\
Non-specified & \multicolumn{2}{|l|}{} \\
\hline Gonadoblastoma & \\
\hline T: Testicular tumor &
\end{tabular}


peaks in the first 3-4 months and at the age of $16(11)$. The most common benign paratesticular tumor at all ages is lipomas (12).

\section{Etiology}

Causes of GCT include cryptorchidism, disorders of sexual development, in-utero estrogen exposure, neonatal jaundice, low or high-birth weight (13-16). Cryptorchidism is one of the most important risk factors for GCT and is associated with $10 \%$ of all cases. Cryptorchidism increases the life-long risk of GCT by four times $(17,18)$. Cancer rate also increases with delay in the orchiopexy (19). Increased incidence of GCT has been observed in patients with disorders of sexual development -particularly hypovirililization and gonadal dysgenesis. The presence of a $\mathrm{Y}$-chromosome in gonadal dysgenesis further increases the risk of tumor, there by raising the incidence to $10 \%$ at the age of 20 (20). YST is non-diploid, but pediatric GCT is usually diploid. It is characterized by $1 p$ deletion, loss of chromosome $6 q$, chromosome 2, and 3p anomalies (21).

\section{Diagnosis and Staging}

TT presents with a painless mass in children. However, it can be detected incidentally in cases such as torsion, scrotal pain, and hydrocele. Physical examination has an important role in the diagnosis of $T$ T. The mass can often be palpated as a painless, solid testicular lesion (4). However, physical examination may be unremarkable. Differential diagnoses include epididymoorchitis, hydrocele, inguinal hernia, and testicular torsion.

Serum tumor markers play an important role in the diagnosis and follow-up. For example, human chorionic gonadotropin $-\beta$ (B-hCG) and alpha feto protein (AFP) are used as serum markers in TT. AFP is produced in the fetal yolk sac, liver, and gastrointestinal tract and has a half-life of five days. It is the most important tumor marker in prepubertal $\Pi \mathrm{T}$ and increases in $90 \%$ of YST. However, in children under 1-year-old, the increase in AFP can be physiological and it may take 6-8 months to reach its normal level $(4,22)$. B-hCG rarely increases in prepubertal tumors, making it not very useful in the diagnosis (23).

Scrotal ultrasonography (US) is the first-choice method for imaging in TT. Doppler US is more beneficial in diagnosis than conventional US (24). Although the US has close to $100 \%$ sensitivity in the diagnosis, its reliability is low in distinguishing malignant from benign lesions. However, the US is useful to distinguish between the testicular and paratesticular tumors and recognize some specific lesions (5). Benign tumors are generally characterized by properly limited lesions with low blood flow. In the US, epidermoid cysts appear as a properly limited cyst containing echogenic debris, YST as a solid mass, and teratomas as a heterogeneous complex lesion with cystic and solid contents (5). Disseminated disease in children is rare. In the case of malignant appearance with elevated AFP values, abdominal CT is advised. It is worthy to note that the most common site of metastasis is the lungs.

The staging described by children's oncology group (COG) is used in the prepubertal period and it is based on the localization of the disease, the presence of metastasis, and the change in the level of the postoperative tumor marker (Table 2). Staging is done between 1 and 4 (25). Postpubertal $T T$ is evaluated according to TNM staging system just as in adults.

\begin{tabular}{|l|l|}
\hline \multicolumn{2}{|l|}{ Table 2. Testicular GCT staging from the COG } \\
\hline Stage & Description \\
\hline I & Local disease, markers normalize after complete resection \\
\hline II & $\begin{array}{l}\text { Transscrotal orchiectomy, microscopic disease in scrotum or } \\
\text { high cord (less than } 5 \mathrm{~cm} \text { from proximal end), less than } 2 \mathrm{~cm} \\
\text { retroperitoneal lymph node or persistently increased tumor } \\
\text { markers }\end{array}$ \\
\hline III & Greater than $2 \mathrm{~cm}$ retroperitoneal lymph nodes \\
\hline IV & Distant metastases \\
\hline $\begin{array}{l}\text { Adapted from Wu and Snyder (24), GCT: Germ cell tumors, COG: Children's } \\
\text { oncology group }\end{array}$ \\
\hline
\end{tabular}

\section{Treatment}

The treatment strategy in the pediatric age group should be chosen carefully because most of them are benign. TSS is gaining grounds as it prevents overtreatment of benign lesions. It should be considered in tumors without a high level of serum AFP and have benign features in the US $(4,5)$. The intraoperative frozen examination has an important role in TSS. Many studies have shown that frozen examination has high sensitivity and specificity $(26,27)$. In case of malignant features with frozen section examination, RIO should be performed. If the final pathology of the excised tumor is benign, further treatment is not required. In adolescents and adults, the standard approach is RIO, since the tumor is more likely to be malignant. Surgical approaches for $\mathrm{TT}$ in children are displayed in Table 3.

\section{GCT}

\section{YST}

YST is the most common malignant TT in the prepubertal period $(4,9,28)$. It occurs especially before the age of 2 and is also called endodermal sinus tumor or juvenile embryonal carcinoma. It is usually characterized by a solid mass and a high level of AFP (2). It is seen as a well-limited, heterogeneous mass in the scrotal US. Schiller Duval bodies, which show a variable histological pattern and appear as two layers of tumor cells surrounding the vessel, are pathognomonic findings in the histological examination of specimens (29).

Although the management of YST is more aggressive in adults, a more conservative approach is upheld in children. The reason for the conservative approach is that it can be recognized at an early stage, AFP can be used as a reliable biomarker, and has pure histology. While $85 \%$ of YST are diagnosed at stage 1 in the prepubertal period, only $35 \%$ are diagnosed in the postpubertal period (30). In the prepubertal period, $40 \%$ hematogenous, $28 \%$ lymphatic, and $20 \%$ mixed (hematogenous and lymphatic) spread have been observed for YST, with the lung as the most common site of metastasis (31). If the tumor is limited to the testicle (stage 1) and AFP decreases after orchiectomy, chemotherapy is not indicated (just follow-up is required) (32). The algorithm for the management of YST is displayed in Figure 1.

The overall recurrence is $20 \%$, therefore serum AFP, PA chest $\mathrm{X}$-ray, and abdominal MRI/CT should be performed every 3 months for the first year. The controls then follow every six 


\begin{tabular}{|c|c|c|}
\hline & Radical inguinal orchiectomy & Testis-sparing surgery with frozen section examination \\
\hline AFP & Elevated & Normal \\
\hline \multirow{2}{*}{ Clinical signs } & $\begin{array}{l}\text { Not enough testicular tissue for sufficient testosterone } \\
\text { production }\end{array}$ & \\
\hline & Distant metastasis & \\
\hline Histological pattern & $\begin{array}{l}\text { 1. Yolk sac tumor } \\
\text { 2. Paratesticular Rhabdomyosarcoma } \\
\text { 3. Immature teratoma } \\
\text { 4. Malign type granulosa CT } \\
\text { 5. Malign type sertoli CT } \\
\text { 6. Gonadoblastoma }\end{array}$ & $\begin{array}{l}\text { 1. Mature teratoma } \\
\text { 2. Epidermoid cyst } \\
\text { 3. Leydig CT } \\
\text { 4. Leiomyoma } \\
\text { 5. Lipoma }\end{array}$ \\
\hline
\end{tabular}

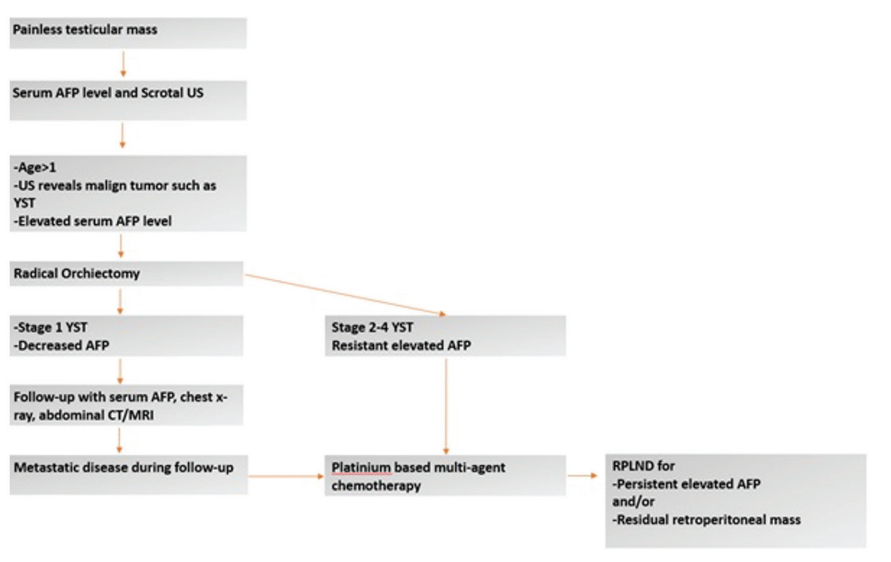

Figure 1. The algorithm for the management of YST

YST: Yolk sac tumor, CT: Computed tomography, AFP: Alpha feto protein, US: Ultrasound, MRI: Magnetic resonance imaging, RPLND: Retroperitoneal lymph node dissection

months in the second year and once a year after the second year (32). In pediatric YST, metastasis occurs in a hematogenous way, unlike in adults (31). Therefore, retroperitoneal lymph node dissection (RPLND) is rarely employed in the management of pediatric TT and should be considered only in patients with chemotherapy and RIO-resistant AFP elevation and residual mass. The use of Platinum-based chemotherapy for TT began in the 1970s and was rearranged for testicular tumor treatment. Chemotherapy provides close to 100\% survival in stage 1 and 95\% in stage 2-4 YST with recurrence after RIO (33-37).

\section{Teratoma}

Teratoma is the second most common type of TT in childhood and consists of all three embryological germ cell layers $(4,9,38)$. It is characterized by a heterogeneous appearance consisting of solid and cystic ultrasonic structures and does not cause an increase in AFP. Mature teratoma is more common than immature teratoma in children. Mature teratomas in the prepubertal period are benign (in contrast to adults) and do not require oncological follow-up $(39,40)$. TSS is the first choice in the treatment of prepubertal mature teratomas $(4,5,38)$. In adolescence, RIO is employed, just as in adults (41).

The immature teratoma contains embryonal or incomplete differential tissue fragments, among which the most primitive neuroectodermal structures are observed (42). In the case of complete resection, pediatric immature teratomas gave a benign course and a low risk of recurrence after surgery (39). $\mathrm{RIO}$ is sufficient for immature teratomas not accompanied by YST (41).

\section{Epidermoid Cyst}

The epidermoid cyst is a monodermal variant of a teratoma and accounts for about $15 \%$ of all pediatric TT $(5,9)$. It is benign in both adults and children and usually expresses normal levels of AFP. In the scrotal US, keratin epithelium such as an onion skin and cyst are observed. It can also be treated with TSS using a frozen examination and no oncological follow-up is required $(5,9,26)$.

\section{Gonadal Stromal Tumors}

\section{Leydig Cell Tumor}

Leydig cell tumor is the most common tumor among gonadal stromal tumors and is often seen between the ages of five and ten. Patients may present with painless testicular mass and early puberty signs due to the secretion of testosterone from Leydig cells. Leydig cell tumor is detected in $10 \%$ of patients with early puberty (43). Feminization signs such as gynecomastia may accompany in approximately $10-15 \%$ of patients (44). Leydig cell tumors are not malignant and can be treated with TSS or RIO, but early puberty findings cannot be reversed $(1,5,41)$.

\section{Juvenile Granulosa Cell Tumor}

Juvenile granulosa cell tumor is a benign tumor that usually appears in the first year of life with a painless testicular mass. It is associated with Y-chromosome structural anomalies, mosaicism, and ambiguous genitalia (45). Solid and cystic structures surrounded by granulosa-like cells are seen in histological preparations. From immunohistochemical evaluation, it can be 
separated by staining with inhibin-alpha from YST (45). It can also be treated with RIO or TSS (46). Recurrence or metastasis is not expected (45).

\section{Sertoli Cell Tumor}

Sertoli cell tumor is the second most common gonadal stromal tumor (47). It is seen in approximately $3 \%$ and common before 10 years of age (48). It is hormonally active in $10 \%$ of patients and can cause gynecomastia or early puberty (49). It is usually benign in children under the age of five but can also be malignant in older children (45). In the presence of metastasis, RPLND, chemotherapy, and radiotherapy are among the treatment options (50). Also, genetic or endocrinological diseases such as Peutz-Jeghers and Carney syndrome are accompanied in one out of three patients, and should be considered during diagnosis (51).

\section{Other Tumors}

\section{Gonadoblastoma}

Gonadoblastomas are generally benign and asymptomatic tumors. It is the most common testicular tumor associated with disorders of sexual development and often found in dysgenetic gonads (45). It is noticed by virilization in individuals with 46 XY karyotypes who have a phenotypically female appearance. Malignant tumors occur in about $10 \%$ of patients and bilateral in $33 \%$ of patients (52). Although it is benign in the neonatal period, it can undergo malignant transformation especially after puberty, and turn into dysgerminoma (45). RIO is recommended in this patient group.

\section{Leukemia-lymphoma}

Leukemia and lymphoma are the most common malignant tumors that metastasize to the testicle in children. In acute lymphoblastic leukemia (ALL), the second most common site of extramedullary metastasis after the central nervous system is the testicle (45). Testicular metastasis in patients with ALL is a poor prognostic factor. Follicular lymphoma may appear as a primary testicular tumor (53). Radiotherapy and systemic chemotherapy are standard treatment options used (23).

\section{Testicular Microlithiasis}

Controversy on this subject continues: some publications have called into question if an association between microlithiasis and GCT exists at all in children, whereas others continue to cite a strong association between microlithiasis and primary TT $(54,55)$.

\section{Paratesticular Tumors}

The paratesticular region consists of the spermatic cord, epididymis, tunica vaginalis, and embryonal residues. Benign and malignant tumors such as leiomyomas, fibromas, lipomas, hemangiomas, rhabdomyomas, and melanotic neuroectodermal tumor scan develop from these tissues.

\section{Lipoma}

The most common tumor of the paratesticular region at all ages is lipomas (12). It occurs as an asymptomatic scrotal mass. It is characterized as a homogeneous hyperechoic lesion in the scrotal US. CT and MR are employed in case of suspicion of malignancy. Symptomatic masses can be locally excised.

\section{Leiomyoma}

It is the second most common epididymis tumor at all ages and usually seen in adults $(12,56)$. These tumors tend to grow slowly. It is displayed as a solid-cystic lesion containing calcification when viewed using scrotal US (57). Due to the lack of metastasis and recurrence, TSS can be performed, but in cases where it is adherent to the testicular tissue, it can be taken out of the body by orchiectomy (11).

\section{Hemangioma}

Scrotal hemangioma is a rare paratesticular lesion mostly seen in infancy. Although it is generally asymptomatic, pain, swelling, and bleeding may occur. It can be mixed with varicocele and magnetic resonance imaging is useful when the scrotal US cannot distinguish specific features. Local excision can be made due to the risk of bleeding and ulceration.

\section{Paratesticular Rhabdomyosarcoma}

Originates from mesenchymal tissue of the paratesticular region. It represents $40 \%$ of all paratesticular malignancies and $5 \%$ of all testicular and paratesticular malignancies (6). The incidence is distributed bimodally and increases at the age of 3-4 months and at 16 years (11). Patients usually present with a painless hard mass. Serum AFP and B-HCG values are observed at normal levels. A heterogeneous mass can be seen in the US, but it cannot provide precise information on whether it is benign or malignant. Although local invasion is common, lymphatic metastasis is observed in $30-40 \%$ of patients (6).

It has four histological subtypes: embryonal, pleomorphic, alveolar, and undifferentiated. Embryonal type is the most common in all RMS and is seen in 60\%. In paratesticular RMS, approximately $97 \%$ of patients appear with this type (58). The algorithm for the management of RMS is displayed in Figure 2.

The Intergroup RMS studies made some recommendations for the treatment of these tumors. According to tem, RIO should be performed in children older than 10 years, and then RPLND and multiagent chemotherapy regardless of the stage. If there

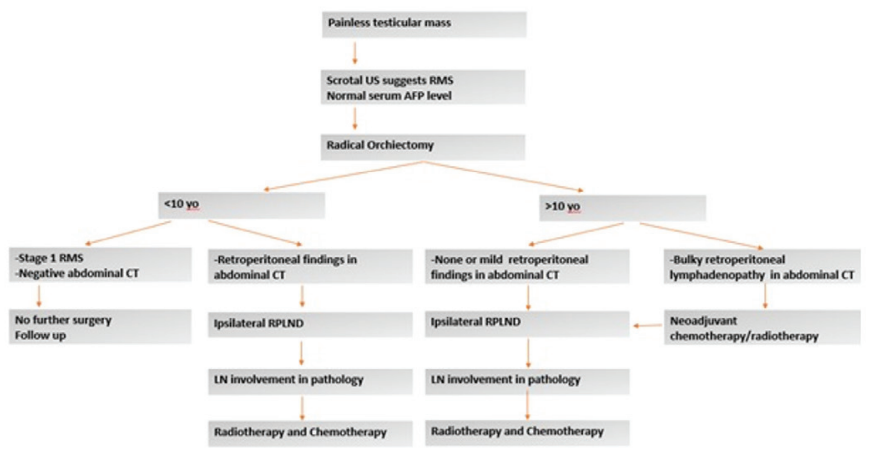

Figure 2. The algorithm for the management of RMS

RMS: Rhabdomyosarcoma, US: Ultrasound, CT: Computed tomography, RPLND: Retroperitoneal lymph node dissection, AFP: Alpha feto protein 
is suspicion of retroperitoneal spreading in patients under 10 years of age, RIO and then RPLND should be performed (59). Although some European Collaborative Groups avoid RPLND, COG recommends RPLND for all children older than 10 years hoping to avoid failure in the retroperitoneum and the burden of second-line therapy. Despite the data supporting these recommendations, an analysis of the SEER database recently published showed that one-third of adolescents still do not undergo RPLND, even at the distinct survival advantage (OS at 5 years $92 \%$ vs. $64 \%$ ) (60). Paratesticular rhabdomyosarcoma has a better prognosis than RMS developing in other parts of the body. The 3-year survival rate is reported at $95 \%$ in paratesticular RMS and $60-70 \%$ in others (61).

\section{Conclusion}

Although childhood testicle and paratesticular tumors are rare, testicular mass requires further evaluation. Detailed history, physical examination, serum AFP level, and the scrotal US are essential for differential diagnosis. RIO is the gold standard treatment method. However, due to the high frequency of benign tumors, TSS is often preferred in appropriate cases.

\section{Acknowledgements}

Publication: The results of the study were not published in full or in part in form of abstracts.

Contribution: There is not any contributors who may not be listed as authors.

Conflict of Interest: No conflict of interest was declared by the authors.

Financial Disclosure: The authors declared that this study received no financial support.

\section{Ethics}

Peer-review: Externally peer-reviewed.

\section{Authorship Contributions}

Supervision: Ç.A.Ş., S.Y., Concept: D.D., Ç.A.Ş., S.Y., Design: D.D., Ç.A.Ş., S.Y., Data Collection or Processing: D.D., Analysis or Interpretation: D.D., Literature Search: D.D., Writing: D.D., S.Y.

\section{References}

1. Brosman SA. Testicular tumors in prepubertal children. Urology 1979;13:581-588.

2. Lee SD; Korean Society of Pediatric Urology. Epidemiological and clinical behavior of prepubertal testicular tumors in Korea. J Urol 2004; 172:674-678.

3. Ross JH, Rybicki L, Kay R. Clinical behavior and a contemporary management algorithm for prepubertal testis tumors: a summary of the Prepubertal Testis Tumor Registry. J Urol 2002;168:1675-1678; discussion 1678-1679.

4. Metcalfe PD, Farivar-Mohseni $H$, Farhat $W$, et al. Pediatric testicular tumors: contemporary incidence and efficacy of testicular preserving surgery. J Urol 2003;170:2412-2415; discussion 2415-2416.

5. J.S. Valla for the Group D'Etude en Urologie Pédiatrique. Testissparing surgery for benign testicular tumors in children. J Urol 2001; 165:2280-2283.

6. Shapiro E, Strother D. Pediatric genitourinary rhabdomyosarcoma. J Urol 1992;148:1761-1768.
7. Kaplan GW, Cromie WC, Kelalis PP, et al. Prepubertal yolk sac testicular tumors--report of the testicular tumor registry. J Urol 1988; 140:1109-1112.

8. Maizlin II, Dellinger M, Gow KW, et al. Testicular tumors in prepubescent patients. J Pediatr Surg 2018;53:1748-1752.

9. Pohl HG, Shukla AR, Metcalf PD, et al. Prepubertal testis tumors: actual prevalence rate of histological types. J Urol 2004;172:2370-2372.

10. Young JL Jr, Miller RW. Incidence of malignant tumors in U. S. children. J Pediatr 1975;86:254-258.

11. Ahmed HU, Arya M, Muneer A, et al. Testicular and paratesticular tumours in the prepubertal population. Lancet Oncol 2010;11:476-483.

12. Beccia D], Krane RJ, Olsson CA. Clinical management of non-testicular intrascrotal tumors. J Urol 1976;116:476-479.

13. Depue RH, Pike MC, Henderson BE. Estrogen exposure during gestation and risk of testicular cancer. J Natl Cancer Inst 1983;71:1151-1155.

14. Ekbom A, Akre O. Increasing incidence of testicular cancer--birth cohort effects. APMIS 1998;106:225-229; discussion 229-231.

15. Richiardi L, Akre O, Bellocco R, et al. Perinatal determinants of germcell testicular cancer in relation to histological subtypes. $\mathrm{Br}$ J Cancer 2002;87:545-550.

16. Reuter VE. Origins and molecular biology of testicular germ cell tumors. Mod Pathol 2005;18(Suppl 2):S51-S60.

17. Schottenfeld D, Warshauer ME, Sherlock S, et al. The epidemiology of testicular cancer in young adults. Am J Epidemiol 1980;112:232-246.

18. Wood HM, Elder JS. Cryptorchidism and testicular cancer: separating fact from fiction. J Urol 2009;181:452-461.

19. Pettersson A, Richiardi L, Nordenskjold A, et al. Age at surgery for undescended testis and risk of testicular cancer. N Engl J Med 2007;356:1835-1841.

20. Grimsby GM, Ritchey ML. Pediatric urologic oncology. Pediatr Clin North Am 2012;59:947-959.

21. Schneider DT, Schuster AE, Fritsch MK, et al. Genetic analysis of childhood germ cell tumors with comparative genomic hybridization. Klin Padiatr 2001;213:204-211.

22. Brewer JA, Tank ES. Yolk sac tumors and alpha-fetoprotein in first year of life. Urology 1993;42:79-80.

23. Palmer JS, Steinberg GD, Kaplan WE. Testicular, Sacrococcygeal, and Other Tumors. Comprehensive Textbook of Genitourinary Oncology. 2nd ed. Lippincott Williams \& Wilkins: Philadelphia, 2000. p. 91-100.

24. Luker GD, Siegel MJ. Pediatric testicular tumors: evaluation with grayscale and color Doppler US. Radiology 1994;191:561-564.

25. Wu HY, Snyder HM. Pediatric urologic oncology: bladder, prostate, testis. Urol Clin North Am 2004;31:619-627, xi.

26. Elert $A$, Olbert $P$, Hegele $A$, et al. Accuracy of frozen section examination of testicular tumors of uncertain origin. Eur Urol 2002;41:290-293.

27. Subik MK, Gordetsky J, Yao JL, et al. Frozen section assessment in testicular and paratesticular lesions suspicious for malignancy: its role in preventing unnecessary orchiectomy. Hum Pathol 2012;43:1514-1519.

28. Walsh TJ, Grady RW, Porter MP, et al. Incidence of testicular germ cell cancers in U.S. children: SEER program experience 1973 to 2000. Urology 2006;68:402-405; discussion 405.

29. Ulbright TM, Roth LM. Recent developments in the pathology of germ cell tumors. Semin Diagn Pathol 1987;4:304-319.

30. Grady RW. Current management of prepubertal yolk sac tumors of the testis. Urol Clin North Am 2000;27:503-508, ix.

31. Grady RW, Ross JH, Kay R. Patterns of metastatic spread in prepubertal yolk sac tumor of the testis. J Urol 1995;153:1259-1261.

32. Connolly JA, Gearhart JP. Management of yolk sac tumors in children. Urol Clin North Am 1993;20:7-14.

33. Schlatter M, Rescorla F, Giller R, et al; Children's Cancer Group; Pediatric Oncology Group. Excellent outcome in patients with stage 
I germ cell tumors of the testes: a study of the Children's Cancer Group/Pediatric Oncology Group. J Pediatr Surg 2003;38:319-324; discussion 319-324.

34. Lo Curto M, Lumia F, Alaggio R, et al. Malignant germ cell tumors in childhood: results of the first Italian cooperative study "TCG 91". Med Pediatr Oncol 2003;41:417-425.

35. Haas RJ, Schmidt $P$, Göbel $U$, et al. Testicular germ cell tumors, an update. Results of the German cooperative studies 1982-1997. Klin Padiatr 1999;211:300-304.

36. Mann JR, Raafat F, Robinson K, et al. The United Kingdom Children's Cancer Study Group's second germ cell tumor study: carboplatin, etoposide, and bleomycin are effective treatment for children with malignant extracranial germ cell tumors, with acceptable toxicity. J Clin Oncol 2000;18:3809-3818.

37. Rogers PC, Olson TA, Cullen JW, et al; Pediatric Oncology Group 9048; Children's Cancer Group 8891. Treatment of children and adolescents with stage II testicular and stages I and II ovarian malignant germ cell tumors: a Pediatric Intergroup Study--Pediatric Oncology Group 9048 and Children's Cancer Group 8891. J Clin Oncol 2004;22:3563-3569.

38. Shukla AR, Woodard C, Carr MC, et al. Experience with testis sparing surgery for testicular teratoma. J Urol 2004;171:161-163.

39. Göbel U, Calaminus G, Engert J, et al. Teratomas in infancy and childhood. Med Pediatr Oncol 1998;31:8-15.

40. Grady RW, Ross JH, Kay R. Epidemiological features of testicular teratoma in a prepubertal population. J Urol 1997;158:1191-1192.

41. Ross JH, Kay R. Prepubertal testis tumors. Rev Urol 2004;6:11-18.

42. Harms D, Zahn S, Göbel U, Schneider DT. Pathology and molecular biology of teratomas in childhood and adolescence. Klin Padiatr 2006;218:296-302.

43. Urban MD, Lee PA, Plotnick $L P$, et al. The diagnosis of Leydig cell tumors in childhood. Am J Dis Child 1978;132:494-497.

44. Coppes MJ, Rackley R, Kay R. Primary testicular and paratesticular tumors of childhood. Med Pediatr Oncol 1994;22:329-340.

45. Cortez JC, Kaplan GW. Gonadal stromal tumors, gonadoblastomas, epidermoid cysts, and secondary tumors of the testis in children. Urol Clin North Am 1993;20:15-26.

46. Shukla AR, Huff DS, Canning DA, et al. Juvenile granulosa cell tumor of the testis:: contemporary clinical management and pathological diagnosis. J Urol 2004;171:1900-1902.
47. Young RH, Koelliker DD, Scully RE. Sertoli cell tumors of the testis, not otherwise specified: a clinicopathologic analysis of 60 cases. Am J Surg Pathol 1998;22:709-721.

48. Thomas JC, Ross JH, Kay R. Stromal testis tumors in children: a report from the prepubertal testis tumor registry. JUrol 2001;166:2338-2340.

49. Gabrilove JL, Freiberg EK, Leiter E, et al. Feminizing and nonfeminizing Sertoli cell tumors. J Urol 1980;124:757-767.

50. Agarwal PK, Palmer JS. Testicular and paratesticular neoplasms in prepubertal males. J Urol 2006;176:875-881.

51. Washecka R, Dresner MI, Honda SA. Testicular tumors in Carney's complex. J Urol 2002;167:1299-1302.

52. Müller J, Ritzén EM, Ivarsson SA, et al. Management of males with 45,X/46, XY gonadal dysgenesis. Horm Res 1999;52:11-14.

53. Finn LS, Viswanatha DS, Belasco JB, et al. Primary follicular lymphoma of the testis in childhood. Cancer 1999;85:1626-1635.

54. Trout AT, Chow J, McNamara ER, et al. Association between testicular microlithiasis and testicular neoplasia: large multicenter study in a pediatric population. Radiology 2017;285:576-583.

55. Volokhina YV, Oyoyo UE, Miller JH. Ultrasound demonstration of testicular microlithiasis in pediatric patients: is there an association with testicular germ cell tumors? Pediatr Radiol 2014;44:50-55.

56. Lioe TF, Biggart JD. Tumours of the spermatic cord and paratesticular tissue. A clinicopathological study. Br J Urol 1993;71:600-606.

57. Hertzberg BS, Kliewer MA, Hertzberg MA, et al. Epididymal leiomyoma: sonographic features. J Ultrasound Med 1996;15:797-799.

58. Maurer HM, Moon T, Donaldson $M$, et al. The intergroup rhabdomyosarcoma study: a preliminary report. Cancer 1977;40:2015-2026.

59. Raney RB, Anderson JR, Barr FG, et al. Rhabdomyosarcoma and undifferentiated sarcoma in the first two decades of life: a selective review of intergroup rhabdomyosarcoma study group experience and rationale for Intergroup Rhabdomyosarcoma Study V. J Pediatr Hematol Oncol 2001;23:215-220.

60. Hamilton EC, Miller CC, Joseph $\mathrm{M}$, et al. Retroperitoneal lymph node staging in paratesticular rhabdomyosarcoma-are we meeting expectations? J Surg Res 2018;224:44-49.

61. Lawrence W Jr, Gehan EA, Hays DM, et al. Prognostic significance of staging factors of the UICC staging system in childhood rhabdomyosarcoma: a report from the Intergroup Rhabdomyosarcoma Study (IRS-II). J Clin Oncol 1987;5:46-54. 